\title{
Within-herd prevalence thresholds for the detection of Mycobacterium avium subspecies paratuberculosis-positive dairy herds using boot swabs and liquid manure samples
}

\author{
K. DONAT ${ }^{1} *$ N. HAHN ${ }^{1}$, T. EISENBERG ${ }^{2}$, K. SCHLEZ ${ }^{2}, H$ H. KÖHLER ${ }^{3}$,

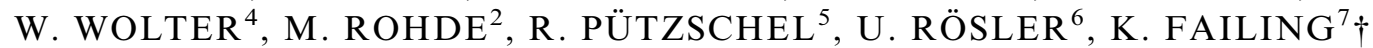 \\ AND P. M. ZSCHÖCK ${ }^{2} \dagger$ \\ ${ }^{1}$ Animal Health Service, Thuringian Animal Diseases Fund, Jena, Thuringia, Germany \\ ${ }^{2}$ Department of Veterinary Medicine, Hessian State Laboratory, Gießen, Hesse, Germany \\ ${ }^{3}$ Institute of Molecular Pathogenesis, Friedrich-Loeffler-Institut, Jena, Thuringia, Germany \\ ${ }^{4}$ Hesse State Council, Wetzlar, Hesse, Germany \\ ${ }^{5}$ Animal Health Service, Saxon Animal Diseases Fund, Dresden, Saxony, Germany \\ ${ }^{6}$ Institute of Animal and Environmental Hygiene, Department of Veterinary Medicine at the Freie Universität \\ Berlin, Berlin, Germany \\ ${ }^{7}$ Unit for Biomathematics and Data Processing, Veterinary Faculty, Justus-Liebig-University, Gießen, Hesse, Germany
}

Received 28 September 2014; Final revision 15 March 2015; Accepted 20 April 2015;

first published online 26 June 2015

\section{SUMMARY}

The control of Johne's disease requires the identification of Mycobacterium avium ssp. paratuberculosis (MAP)-positive herds. Boot swabs and liquid manure samples have been suggested as an easy-to-use alternative to sampling individual animals in order to diagnose subclinical Johne's disease at the herd level, but there is a need to evaluate performance of this approach in the field. Using a logistic regression model, this study aimed to calculate the threshold level of the apparent within-herd prevalence as determined by individual faecal culture, thus allowing the detection of whether a herd is MAP positive. A total of 77 boot swabs and 75 liquid manure samples were taken from 19 certified negative and 58 positive dairy herds. Faecal culture, three different polymerase chain reaction (PCR) methods and the combination of faecal culture with PCR were applied in order to detect MAP. For 50\% probability of detection, a within-herd prevalence threshold of $1.5 \%$ was calculated for testing both matrices simultaneously by faecal culture and PCR, with the threshold increased to $4.0 \%$ for $90 \%$ probability of detection. The results encourage the use of boot swabs or liquid manure samples, or a combination both, for identifying MAP-positive herds and, to a certain extent, for monitoring certified Johne's disease-negative cattle herds.

Key words: Boot swabs, herd-level diagnosis, infectious disease control, Mycobacterium (avium paratuberculosis), veterinary epidemiology.

\section{INTRODUCTION}

Johne's disease, or paratuberculosis, is a chronic granulomatous enteritis predominantly found in ruminants, which is caused by Mycobacterium avium subspecies paratuberculosis (MAP). MAP infection is believed to happen in the first year of life, although initial clinical

\footnotetext{
* Author for correspondence: Dr K. Donat, Thüringer Tierseuchenkasse, Victor-Goerttler-Straße 4, D-07745 Jena, Germany. (Email: kdonat@thueringertierseuchenkasse.de)

$\dagger$ These authors contributed equally as joint senior authors.
} 
symptoms can only be observed months or even years after infection. Animals suffer from therapy-resistant profuse diarrhoea, meaning that cachexia and the development of oedema due to hypoproteinaemia are typical symptoms in the late stage of the disease [1]. Economic losses are caused by reduced slaughter weight [2], increased susceptibility to other diseases [3], premature culling [4] and, with regard to the dairy industry, reduced lactation performance even in cows with no clinical symptoms [5-8]. Furthermore, many authors discuss the zoonotic potential of MAP in the pathogenesis of Crohn's disease, a form of granulomatous enteritis in humans $[9,10]$.

With respect to the economic impact of Johne's disease and the presumed zoonotic potential of MAP, effective measures to control the disease should be implemented in MAP-positive herds in order to limit prevalence and thus shedding of the agent into the environment as well as to prevent it from being carried over into the food chain. The first step towards implementing control measures within a herd is the identification of a herd as being MAP positive.

Sampling individual animals in order to identify infected herds has its limitations. While faecal culture applied on individual faecal samples is still considered the most sensitive method, it is labour-intensive, timeconsuming and costly [11]. Applying polymerase chain reaction (PCR) on faecal samples allows the detection of MAP in a relatively short time, but it is also expensive. Sensitivity and specificity vary according to the method applied [12]. Both depend on the DNA extraction procedures, which must ensure an effective removal of PCR inhibitors like phytic acid, polysaccharides, phenols or bile salts [13]. ELISA testing for MAP antibodies on selected animals is hampered by limited diagnostic sensitivity and specificity compared to detecting organisms, and also by the resulting difficulties when interpreting results with low numbers of reactors [14, 15].

Environmental sampling protocols have been developed and evaluated over several years [16-22]. The herd-level sensitivity of environmental sampling depends on the number of samples and within-herd prevalence (WHP), and varies widely from $\sim 30 \%$ to $\sim 90 \%$ [23]. It was estimated to be $\sim 70 \%$ when sampling one set of six environmental samples in lowprevalence herds [24]. A recent study calculated thresholds of MAP shedders' apparent within-herd prevalence $\left(\mathrm{WHP}_{\mathrm{app}}\right)$ that allow the detection of a MAP-positive herd at different probabilities $\left(P_{\mathrm{d}}\right)$ $\left(\sim 3 \%\right.$ at $\left.50 \% \quad P_{\mathrm{d}}\right)$, which demonstrates that environmental sampling is capable of identifying herds with a low prevalence but has limitations in herds with very low $\mathrm{WHP}_{\text {app }}$ [25].

As one option, sampling socks as known from Salmonella testing (boot swabs) have been suggested as an easily accessible matrix for MAP detection in dairy herds [26, 27], and have been studied in a longitudinal approach. It was possible to detect high-prevalence herds with a high degree of accuracy by repeatedly taking one sample per herd [26]. Performance in herds with low prevalence has yet to be clarified. As such, data regarding the sensitivity of this approach is necessary in order to assess its applicability in the field.

Various authors emphasize bacterial culture of environmental samples as a suitable tool for MAP detection in dairy herds with moderate to high WHP [16-20]. This approach utilizes the lengthy survival of MAP under environmental conditions [28, 29]. Recently, quantitative real-time PCR protocols for the detection of MAP combined with high-efficiency DNA extraction were evaluated, identifying more individual faecal samples [30] and more environmental samples [31] as MAP positive than with faecal culture on Herrold's egg yolk medium. Although these results also suggest an acceptable test performance of a PCR using boot swabs, this matrix has not yet been evaluated.

First, we hypothesize that sampling boot swabs and liquid manure is sufficient to detect MAP-positive herds when faecal culture as well as PCR are applied; and second, that the environmental sampling approach is suitable to identify MAP-positive dairy herds at an acceptable probability level even if the $\mathrm{WHP}_{\mathrm{app}}$ is low and only one or two environmental samples are collected. Therefore, our study aimed to estimate $\mathrm{WHP}_{\text {app }}$ thresholds of this approach at different probability levels, applying both PCR and faecal culture simultaneously or separately.

\section{MATERIALS AND METHODS}

\section{Study population}

A total of 77 dairy herds in Thuringia, Hesse and Saxony, all federal states of Germany, with an average herd size of 356 cows per herd (27-1170) were selected for this study. All herds were housed in free stalls. The herds in Thuringia and Saxony had been enrolled in voluntary control programmes of bovine Johne's disease for several years; these are organized by Thuringia and Saxony's respective animal health services [32, 33]. Among other measures, the programmes include annual 
screenings of all lactating and dry cows, including breeding bulls, for MAP by faecal culture. Depending on herd size and herd management aspects, these animals are all sampled for testing either on one day per year or in a continuous manner in connection with other management measures (e.g. puerperal controls, pregnancy tests, drying off). Herds which never had a faecal culture-positive test result in the annual herd screenings over three consecutive years are certified as 'herds not suspected of having paratuberculosis'. The rigour of this certification corresponds to level 6 of the Uniform Program Standards for the Voluntary Bovine Johne's Disease Control Program of the United States Department for Agriculture [34]. In the present study, herds were selected whose owners had agreed to take part in this project $(n=67)$. In Hesse, all herds included in the present study were found to contain at least one MAP shedder during a previous regional MAP survey conducted in 2007, which was based on individual serological testing with subsequent faecal culture. Several subsequent studies examined these herds during the following years [26], but effective control measures were never implemented and the herds remained MAP positive. The Hessian herds were subjected to ad hoc $\mathrm{WHP}_{\text {app }}$ determination at the time of environmental sampling $(n=10)$.

\section{Individual faecal sampling and determination of herd prevalence}

Individual faecal samples were taken directly from the rectum and immediately transported to the laboratory for further processing. $\mathrm{WHP}_{\mathrm{app}}$ of MAP shedders was calculated as the proportion of faecal culture-positive cows in the total cows sampled from the herd. In Hesse, individual as well as environmental samplings were conducted at the same time since no previous data on individual faecal culture existed. By contrast, in Thuringia and Saxony the latest individual cows' faecal culture results obtained during the preceding year were used in order to estimate $\mathrm{WHP}_{\mathrm{app}}$. A list of individuals that were kept in the herd on the day of environmental sampling was taken from the German database of animal origin (HI-Tier) and adjusted to the data in the laboratory database, extracting the test results for all cows after first calving and bulls aged $>24$ months.

\section{Boot swabs and liquid manure sampling}

Boot swab samples were collected as described by Eisenberg et al. [26] during September and
December 2012. Two samplers walked around, mainly in areas with high cow traffic, collecting four boot swab samples in parallel. Sampling involved manure concentration areas where most of the cows commingled and which had proven suitable for environmental sampling in previous studies [16, 19, 20]: main cow alleyways, travel routes, crossovers, waiting pen, lactating cow pens. To achieve rough standardization, walking was limited to at least 100 and not more than 200 steps. Basically, walking involved the normal route of a lactating cow to the milking parlour, starting in the lactating cows' pen and ending in the waiting pen. After sampling, the boot swabs were removed; three boot swabs coated well in manure were placed in the inner of two nested aseptic plastic bags, of which the outermost was labelled to ensure correct identification.

Additionally, samples from liquid manure storage areas (tanks, lagoons, pits or pre-flooders) were obtained at the same time by submerging a sampling container up to $10 \mathrm{~cm}$ beneath the surface of the manure. At least $50 \mathrm{ml}$ manure was decanted into a sterile $125 \mathrm{ml}$ plastic cup with screw cap. All the samples were transported in a cooler to the laboratory within $3 \mathrm{~h}$. All samples were stored at $-20^{\circ} \mathrm{C}$. For further processing, boot swabs were cut into small pieces and handled as described by Eisenberg et al. [26].

\section{Bacterial culture}

The faecal culture of individual liquid manure as well as prepared boot swab samples was done on Herrold's egg yolk medium according to the official manual of diagnostic procedures published by the FriedrichLoeffler-Institut, the German Federal Research Institute of Animal Health [35]. Differentiation of characteristic colonies was performed by Ziehl-Neelsen staining and PCR [36]. Samples were characterized as faecal culture-positive or faecal culture-negative. The amount of colony-forming units (c.f.u.) on the surface of the culture medium was scored semi-quantitatively, with 1-10 c.f.u. as ' + ', 11-50 c.f.u. as ' ++ ' and $51-100$ c.f.u. as ' +++ '. If there were $>100$ c.f.u. on the surface, growth was characterized as ' ++++ '.

\section{DNA isolation from faeces, DNA amplification and PCR}

Since different methods for DNA preparation and PCR were used by each laboratory, the respective methodologies are presented separately with the 
following abbreviations: Hessian State Laboratory (laboratory A): PCR A; Thuringian Animal Health Service (laboratory B): PCR B; Friedrich-LoefflerInstitut (laboratory C): PCR C.

\section{PCR A}

The liquid manure and prepared boot swab samples were processed according to the established bacterial culture protocol as an enrichment step. After 4 weeks of incubation at $37^{\circ} \mathrm{C}$, culture surface runoffs were harvested from each of the tubes and investigated by F57/IC real-time PCR. Duplex F57/IC real-time PCR was developed as a modification of a method published previously [37, 38]. The modified $20 \mu 1$ PCR mixture for the duplex real-time PCR assay contained $1 \mu \mathrm{l}$ of the primers F57-F (5'-TAC GAG CAC GCA GGC ATTC-3') and F57-R (5'-CGG TCC AGT TCG CTG TCAT-3') (10 pmol $/ \mu \mathrm{l}), 0.63 \mu \mathrm{l}$ F57 TaqMan probe (5'-CY5-CCT GAC CCT TCBHQ1-3') $(10 \mathrm{pmol} / \mu \mathrm{l}), 125$ copies of internal amplification control (IAC) DNA, 0.5 $\mu$ l EGFP 4(5) mix [39], $10 \cdot 0 \mu 12 \times$ Quantitect Multiplex Master Mix No Rox (Qiagen, Germany), and a $5 \mu \mathrm{l}$ aliquot of the DNA sample. EGFP 4(5) mix contains $2 \cdot 5 \mathrm{pmol} / \mu 1$ of each primer EGFP-11-F (5'-CAG CCA CAA CGT CTA TAT CAT G-3'), EGFP-10-R (5'-CTT GTA CAG CTC GTC CAT GC-3') and $1.25 \mathrm{pmol} / \mu \mathrm{l}$ EGFP1HEX probe (5'-HEX-AGC ACC CAG TCC GCC CTG AGC A-BHQ1-3').

The PCR tubes were then placed in a thermocycler (Mx3005 P, Stratagene, Germany) with a pre-heated lid and subjected to initial denaturation at $95^{\circ} \mathrm{C}$ for $15 \mathrm{~min}$ followed by 50 cycles of denaturation at $94^{\circ} \mathrm{C}$ for $1 \mathrm{~min}$ each and annealing and extension at $60^{\circ} \mathrm{C}$ for $90 \mathrm{~s}$ each. Analysis of fluorescence was performed using Mx3000 P software (Stratagene). Amplification curves were carefully analysed after checking raw fluorescence values, baseline settings and the threshold as recommended by the manufacturer. Positive signals were recorded as cycle threshold $\left(\mathrm{C}_{\mathrm{t}}\right)$ values.

\section{PCR B}

The general protocol utilized represented a commercially available integrated work flow including DNA isolation from faeces, DNA amplification and qPCR that was licensed in Germany for the detection of MAP from individual faecal samples and environmental faecal samples (Life Technologies $\mathrm{GmbH}$, Germany). The DNA was extracted from faeces using the MagMax ${ }^{\mathrm{TM}}$ Total Nucleic Acid Isolation kit, using the MagMax ${ }^{\mathrm{TM}}$ Express 96 instrument (Life Technologies $\mathrm{GmbH}$ ) according to the manufacturer's instructions; it uses magnetic beads to separate the DNA from the faeces. To detect MAP DNA, the VetMAX ${ }^{\text {TM }}$ MAP Real-Time PCR Screening kit, performed on a 7500 fast real-time PCR cycler (Life Technologies $\mathrm{GmbH}$ ), was applied according to the manufacturer's instructions. A sample was identified as positive if $C_{t}$ values were $\leqslant 37 \cdot 0$, and negative if $\mathrm{C}_{\mathrm{t}}$ values were $>37 \cdot 0$.

\section{PCR C}

A commercially available qPCR protocol was used. The DNA was extracted from faeces using a commercial nucleic acid isolation kit (QIAamp DNA Mini kit, Qiagen) after pre-concentration of samples using Adiafilter (Adifil 100, Adiagene, France) according to the manufacturer's instructions. The filter system performed the centrifiltration of $10 \mathrm{ml}$ faecal supernatant to concentrate bacteria, enabling an increase in the sensitivity of the global PCR method. In order to detect MAP DNA, a commercial IS900based real-time PCR method (Adiavet Paratb, Adiagene) was used according to the manufacturer's instructions. A sample was identified as positive if $\mathrm{C}_{\mathrm{t}}$ values were $<38 \cdot 0$, and inconclusive for $C_{t}$ values between $38 \cdot 0$ and $40 \cdot 0$.

\section{Statistical data analysis}

Data recording and editing as well as descriptive statistics and $\mathrm{WHP}_{\mathrm{app}}$ computation were performed using a Microsoft Excel spreadsheet (Microsoft Corporation, USA). The statistical software package BMDP/Dynamic (Release 8.1; W. J. Dixon, Statistical Solutions Ltd, Ireland) was used for all other statistical analyses [40]. A statistical significance level of $\alpha=0.05$ was used in general.

In the first step of the data analysis, Spearman's rank correlation coefficient $\left(r_{s}\right)$ was calculated for each matrix in order to analyse the relationship between $\mathrm{WHP}_{\text {app }}$ on the one hand and the semiquantitative colony growth score or the $\mathrm{C}_{t}$ values (qPCR) of boot swabs and liquid manure samples on the other.

Concerning $\mathrm{WHP}_{\text {app }}$ of a certain herd as an influencing factor of interest $(n=77)$, its relation to the dichotomized MAP findings (negative or positive; MAP status) in the samples (boot swabs or liquid manure or combination of both), each determined by 
faecal culture and PCR in each of three laboratories was assessed using a logistic regression model analysed using the asymptotic logistic regression procedure BMDPLR [40]. The applicability of the underlying logistic model was tested with the goodness-of-fit $\chi^{2}$ test and the Hosmer-Lemeshow goodness-of-fit test to verify that the model fitted the data adequately. Additionally, the linear associations between the logit of the outcomes and $\mathrm{WHP}_{\text {app }}$ as the numeric predictor were examined by scattergrams. This assumption in particular is important for the reversibility of the logistic equation to estimate $\mathrm{WHP}_{\mathrm{app}}$ thresholds to given probabilities (see below).

The findings of the boot swab and liquid manure samples were presented for three outcomes: PCR, faecal culture and both tests applied simultaneously.

The findings of the boot swab and liquid manure samples were combined to a single binary outcome (MAP status), being positive if at least one of these matrices showed a positive result, and negative if both matrices tested negatively.

Inversion of the logistic function yields an estimate of $\mathrm{WHP}_{\text {app }}$ related to a given $P_{\mathrm{d}}$ of a herd as MAP positive. For practical reasons, a high $P_{\mathrm{d}}($ e.g. $=0.9)$ is desirable in control programmes or for prevalence estimation. At $P_{\mathrm{d}}=0.9$ the slope of the logistic function is still rising steeply enough, thus limiting the uncertainty of $\mathrm{WHP}_{\mathrm{app}}$ estimation. Additionally, the point of maximal slope $\left(P_{\mathrm{d}}=0.5\right)$ was selected in the analysis, because this is the point of inflection of the sigmoid logistic function. This minimizes the inaccuracy of the $\mathrm{WHP}_{\text {app }}$ estimation when dropping the perpendicular at the $\mathrm{WHP}_{\text {app }}$ axis.

By means of maximum-likelihood techniques [40], $\mathrm{WHP}_{\text {app }}$ thresholds as well as asymptotic standard errors for these detection thresholds were estimated from the data using the program BMDPLE [40]. Approximate 95\% confidence intervals (CIs) for the thresholds of interest were computed using the asymptotic standard errors.

The formula of the logistic model used is

$$
\begin{aligned}
P_{\mathrm{d}} & =\operatorname{probability}(\text { herd }=+) \\
& =\exp \left(a+b \cdot \mathrm{WHP}_{\text {app }}\right) /\left(1+\exp \left(a+b \cdot \mathrm{WHP}_{\text {app }}\right)\right),
\end{aligned}
$$

leading to the $\mathrm{WHP}_{\text {app }}$ threshold formula:

$$
\mathrm{WHP}_{\text {app }}\left(P_{\mathrm{d}}\right)=\left(\ln \left(P_{\mathrm{d}} /\left(1-P_{\mathrm{d}}\right)\right)-a\right) / b,
$$

where $P_{\mathrm{d}}=$ desired probability of detection (absolute number, not in per cent); $\mathrm{WHP}_{\mathrm{app}}(P)=$ apparent within-herd prevalence with detection probability $P ; a=$ constant parameter in the logistic function; $b=$ model coefficient relating to $\mathrm{WHP}_{\text {app }}$ in the logistic regression; $\ln =$ natural logarithm.

\section{RESULTS}

WHP $_{\text {app }}$

A total of 22057 faecal culture test results (883 MAP positive and 21174 MAP negative) were used to calculate $\mathrm{WHP}_{\text {app. }}$. The average sample size was 272 (minimum 11, maximum 916) cows per herd. On average, $86 \cdot 8 \%$ of the cows kept in the herd at the time of environmental sampling had valid individual faecal culture test results allowing estimation of $\mathrm{WHP}_{\mathrm{app}}$ (Table 1). Cows that were introduced into the herd between the date of environmental sampling and individual sampling diminished the percentage of cows with valid test results, as shown in Table 1. Samples from one herd with 27 cows showed an unexpectedly high percentage of bacterial and fungal contamination which resulted in 17 non-analysable samples. Since one sample was MAP positive and the calculated $\mathrm{WHP}_{\mathrm{app}}$ of $9 \cdot 1 \%$ was found to be in the expected range, the herd was not excluded from the study.

\section{Environmental samples}

Apart from one boot swab (laboratory C), all 77 boot swab and 75 liquid manure samples were analysable with faecal culture in each laboratory. Positive and negative results of the PCR tests and the corresponding faecal culture results are given in Table 2. Out of 77 boot swabs, three or four were not analysable in PCR B or PCR C, while none were not analysable in PCR A. Because of solid dung systems, two herds did not supply liquid manure samples, which is why 75 samples were tested. Of these, seven samples in PCR B and five in PCR C were not analysable because of inconclusive $C_{t}$ values.

\section{Association between $\mathrm{WHP}_{\text {app }}$ and faecal culture or qPCR results}

Spearman's rank correlation coefficients for the relationship between $\mathrm{WHP}_{\text {app }}$ and colony growth score in faecal culture or the $C_{t}$ values of each qPCR are given in Table 3 . All test methods showed a significant correlation with $\mathrm{WHP}_{\text {app }}(P<0.0001)$, with the best association between $\mathrm{WHP}_{\text {app }}$ and the $\mathrm{C}_{\mathrm{t}}$ values seen in PCR B. 
Table 1. Herd size, sample size and estimated apparent within-herd prevalence (WHP $\left.P_{\text {app }}\right)$ of 77 herds

\begin{tabular}{llllll}
\hline \hline & Minimum & First quartile & Median & Third quartile & Maximum \\
\hline Herd size $(n)$ & 27 & 115 & 200 & 472 & 1170 \\
Sample size $(n)^{*}$ & 11 & 85 & 204 & 402 & 916 \\
Sample size $(\%) \dagger$ & $33 \cdot 4$ & $71 \cdot 1$ & $86 \cdot 8$ & $93 \cdot 2$ & $100 \cdot 0$ \\
MAP-positive cows $(n)$ & 0 & 0 & 12 & 15 & 87 \\
MAP-negative cows $(n)$ & 10 & 73 & 204 & 377 & 916 \\
$\mathrm{WHP}_{\text {app }}(\%) \dagger$ & $0 \cdot 0$ & $0 \cdot 0$ & $2 \cdot 4$ & $9 \cdot 0$ & $46 \cdot 8$ \\
\hline
\end{tabular}

MAP, Mycobacterium avium ssp. paratuberculosis.

* Number of cows kept in the herd on the day of environmental sampling and which tested positively or negatively for MAP. $\dagger$ Relation of sample size to herd size on the day of environmental sampling.

\$ Apparent within-herd prevalence on the day of environmental sampling.

Table 2. Number of boot swabs and liquid manure samples which tested negatively or positively by FC in three different laboratories and using three different PCR methods ( $A, B, C)$ for MAP

\begin{tabular}{|c|c|c|c|c|c|c|c|c|}
\hline \multirow[b]{4}{*}{ Matrix } & & & \multicolumn{6}{|c|}{ Laboratory } \\
\hline & & & A & & B & & $\mathrm{C}$ & \\
\hline & \multirow{2}{*}{\multicolumn{2}{|c|}{$\begin{array}{l}\text { Method of MAP } \\
\text { detection }\end{array}$}} & PCR & & PCR & & PCR & \\
\hline & & & Pos. & Neg. & Pos. & Neg. & Pos. & Neg \\
\hline \multirow[t]{2}{*}{ Boot swab } & $\mathrm{FC}$ & Pos. & 31 & 9 & 31 & 5 & 34 & 6 \\
\hline & & Neg. & 3 & 34 & 3 & 35 & 3 & 29 \\
\hline \multirow[t]{2}{*}{ Liquid manure } & $\mathrm{FC}$ & Pos. & 28 & 11 & 30 & 5 & 19 & 2 \\
\hline & & Neg. & 1 & 35 & 3 & 30 & 19 & 30 \\
\hline
\end{tabular}

FC, Faecal culture; PCR, quantitative real-time polymerase chain reaction; MAP, Mycobacterium avium ssp. paratuberculosis; Pos., MAP-positive; Neg., MAP-negative.

Table 3. Spearman's rank correlation coefficient for the correlation between within-herd prevalence and colony growth score of the faecal culture in three laboratories $(A, B$ and $C)$ or $C_{t}$ values of three PCR methods $(A, B$ and $C)$ for boot swabs and liquid manure samples from 77 dairy herds

\begin{tabular}{|c|c|c|c|c|}
\hline \multirow[b]{3}{*}{ Test method and laboratory } & \multicolumn{4}{|l|}{ Matrix } \\
\hline & \multicolumn{2}{|c|}{ Boot swabs } & \multicolumn{2}{|c|}{ Liquid manure samples } \\
\hline & $r_{s}$ & $P$ value & $r_{s}$ & $P$ value \\
\hline \multicolumn{5}{|l|}{ FC (colony score*) } \\
\hline A & $0 \cdot 7554$ & $<0.0001$ & $0 \cdot 7628$ & $<0 \cdot 0001$ \\
\hline $\mathrm{B}$ & $0 \cdot 7538$ & $<0 \cdot 0001$ & 0.7937 & $<0 \cdot 0001$ \\
\hline $\mathrm{C}$ & $0 \cdot 7857$ & $<0 \cdot 0001$ & 0.6272 & $<0 \cdot 0001$ \\
\hline \multicolumn{5}{|l|}{$\operatorname{PCR}\left(\mathrm{C}_{\mathrm{t}}\right.$ value $\left.\dagger\right)$} \\
\hline A & $-0 \cdot 6686$ & $<0.0001$ & $-0 \cdot 6693$ & $<0 \cdot 0001$ \\
\hline $\mathrm{B}$ & $-0 \cdot 7589$ & $<0.0001$ & $-0 \cdot 8089$ & $<0.0001$ \\
\hline $\mathrm{C}$ & $-0 \cdot 7211$ & $<0 \cdot 0001$ & $-0 \cdot 7676$ & $<0.0001$ \\
\hline
\end{tabular}

PCR, Polymerase chain reaction; MAP, Mycobacterium avium ssp. paratuberculosis; FC, faecal culture; $\mathrm{C}_{\mathrm{t}}$, cycle threshold; $r_{s}$, Spearman's rank correlation coefficient.

* Colony score of samples' faecal culture test (c.f.u.): +, 1-10; ++, 11-50; +++, 51-100; ++++, >100.

$\dagger \mathrm{C}_{\mathrm{t}}$ value of environmental samples' PCR. 
Table 4. Results of the different logistic regressions to analyse the associations between MAP status of herds $(n=77)$ determined by different methods (FC or PCR or the combination of both) applied to boot swabs and liquid manure samples in three different laboratories (outcomes of interest) and the $W H P_{\text {app }}$ as the predictor

\begin{tabular}{|c|c|c|c|c|c|c|c|c|c|c|}
\hline \multirow[b]{2}{*}{ Matrix } & \multirow[b]{2}{*}{ Lab. } & \multicolumn{3}{|c|}{$\begin{array}{l}\text { MAP status detected by PCR } \\
\text { alone }\end{array}$} & \multicolumn{3}{|c|}{$\begin{array}{l}\text { MAP status detected by faecal } \\
\text { culture alone }\end{array}$} & \multicolumn{3}{|c|}{$\begin{array}{l}\text { MAP status detected by faecal } \\
\text { culture and PCR combined }\end{array}$} \\
\hline & & $\begin{array}{l}\text { Regression } \\
\text { coefficient } \pm \text { S.E. }\end{array}$ & OR & $P$ value* & $\begin{array}{l}\text { Regression } \\
\text { coefficient } \pm \text { s.E. }\end{array}$ & OR & $P$ value & $\begin{array}{l}\text { Regression } \\
\text { coefficient } \pm \text { S.E. }\end{array}$ & OR & $P$ value \\
\hline \multicolumn{11}{|c|}{ Boot swabs } \\
\hline & A & $0 \cdot 274 \pm 0 \cdot 072$ & $1 \cdot 31$ & $0 \cdot 0003$ & $0.503 \pm 0.129$ & $1 \cdot 65$ & $<0 \cdot 0001$ & $0.570 \pm 0.153$ & $1 \cdot 77$ & $0 \cdot 0001$ \\
\hline & B & $0 \cdot 490 \pm 0 \cdot 119$ & $1 \cdot 63$ & $<0.0001$ & $0 \cdot 421 \pm 0 \cdot 104$ & $1 \cdot 52$ & $<0 \cdot 0001$ & $0 \cdot 489 \pm 0 \cdot 124$ & 1.63 & $0 \cdot 0001$ \\
\hline & $\mathrm{C}$ & $0.331 \pm 0.089$ & $1 \cdot 39$ & $0 \cdot 0002$ & $0 \cdot 800 \pm 0.215$ & $2 \cdot 23$ & $<0 \cdot 0001$ & $0 \cdot 634 \pm 0.172$ & $1 \cdot 89$ & $0 \cdot 0001$ \\
\hline \multicolumn{11}{|c|}{ Liquid manure samples } \\
\hline & A & $0.305 \pm 0.078$ & $1 \cdot 36$ & $0 \cdot 0001$ & $0 \cdot 606 \pm 0 \cdot 161$ & $1 \cdot 83$ & $<0 \cdot 0001$ & $0.558 \pm 0.151$ & $1 \cdot 75$ & $0 \cdot 0001$ \\
\hline & B & $0 \cdot 574 \pm 0 \cdot 155$ & $1 \cdot 77$ & $0 \cdot 0001$ & $0 \cdot 531 \pm 0 \cdot 140$ & $1 \cdot 70$ & 0.0001 & $0 \cdot 625 \pm 0 \cdot 170$ & 1.87 & 0.0001 \\
\hline & $\mathrm{C}$ & $0 \cdot 477 \pm 0 \cdot 131$ & $1 \cdot 61$ & $0 \cdot 0002$ & $0.290 \pm 0.073$ & $1 \cdot 34$ & $<0 \cdot 0001$ & $0.523 \pm 0.142$ & $1 \cdot 69$ & $0 \cdot 0002$ \\
\hline
\end{tabular}

MAP, Mycobacterium avium ssp. paratuberculosis; FC, faecal culture; PCR, polymerase chain reaction; WHP $_{\text {app}}$, apparent within-herd prevalence; S.E., standard error; OR, odds ratio.

* $P$ value for odds ratio.

\section{Association between $\mathrm{WHP}_{\text {app }}$ and herds' MAP status as determined by faecal culture or PCR}

Shown by logistic regression, the MAP status as determined by each faecal culture or each PCR was significantly associated with $\mathrm{WHP}_{\text {app }}$ (Table 4). An adequate model fit was verified by the goodness-of-fit $\chi^{2}$ test as well as the Hosmer-Lemeshow goodnessof-fit test and by the inspection of an approximate linear association between the logit of the outcome and the $\mathrm{WHP}_{\text {app. }}$ The regression coefficients resulting from the logistic regression model were all statistically significantly positive, indicating increasing MAP detection probabilities with increasing $\mathrm{WHP}_{\text {app }}$. The corresponding odds ratios (OR) ranged between 1.31 and 1.83 ( $2 \cdot 23$ in one case), showing a corresponding mean rise of the odds of detection of MAP when WHP increases by $1 \%$. Applying both the faecal culture and the PCR methods simultaneously in the same laboratory resulted in slightly increased median OR in the range of 1.63 and 1.89 .

\section{Estimates of the $\mathrm{WHP}_{\text {app }}$ relating to a given $\boldsymbol{P}_{\mathrm{d}}$}

For boot swabs, the lowest thresholds were estimated when faecal culture $\mathrm{C}$ was applied $\left(P_{\mathrm{d}} 50 \%: 2.54 \pm\right.$ $0 \cdot 49 \% ; P_{\mathrm{d}} 90 \%: 5 \cdot 29 \pm 1 \cdot 05 \%$ ) (Tables 5 and 6 ). If liquid manure samples were used alone, analysing faecal culture A as well as all PCR test outcomes resulted in comparable estimates for $P_{\mathrm{d}} 50 \%$ and slightly higher estimates for $P_{\mathrm{d}} 90 \%$. The outcomes for faecal culture $\mathrm{C}$ were considerably higher, which is caused by a markedly lower number of positive test results, obviously because cultivation was performed 9 months later than in laboratories $\mathrm{A}$ and $\mathrm{B}$ and storage at $-20^{\circ} \mathrm{C}$ did not completely prevent degradation of viable bacteria. The distinctly higher estimates for PCR A indicate a lower sensitivity of this method compared to PCR B and PCR C.

Simultaneous testing by faecal culture together with PCR methods led to slightly lower $\mathrm{WHP}_{\text {app }}$ thresholds in each laboratory compared to faecal culture results. PCR C together with faecal culture $\mathrm{C}$ applied on boot swabs $\left(P_{\mathrm{d}} 50 \%: 2 \cdot 39 \pm 0 \cdot 54 \% ; P_{\mathrm{d}} 90 \%: 5 \cdot 85 \pm 1 \cdot 24 \%\right)$ and PCR B together with faecal culture B applied on liquid manure samples $\left(P_{\mathrm{d}} 50 \%: 2.57 \pm 0 \cdot 56 \% ; P_{\mathrm{d}}\right.$ 90\%: $6.08 \pm 1 \cdot 28 \%$ ) showed the lowest estimates for a single sample. The best results were obtained when the results of both samples were included in the model. Again, the lowest $\mathrm{WHP}_{\text {app }}$ thresholds were estimated for PCR $\mathrm{C}$ and faecal culture $\mathrm{C}$ applied on a combined set of boot swab and liquid manure samples $\left(P_{\mathrm{d}} 50 \%\right.$ : $1 \cdot 49 \pm 0 \cdot 39 \% ; P_{\mathrm{d}} 90 \%: 3.99 \pm 0 \cdot 90 \%$; Fig. 1$)$.

\section{DISCUSSION}

In order to control paratuberculosis in cattle herds, it is necessary to identify MAP-positive herds, to focus on these herds, and to persuade farmers to enrol in voluntary control programmes and implement control measures in their herds. As sampling individual animals in order to identify infected herds has its limitations, testing environmental samples by faecal culture 
Table 5. Estimates of $W H P_{\text {app }}$ threshold value \pm asymptotic S.E. and $95 \% C I_{\text {app }}$ for the detection of a MAP-positive herd using a boot swab or a liquid manure sample or the combination of both applying $F C$ (three different laboratories $A, B, C$ ), PCR (three different methods $A, B, C$ ) or the combination of each PCR with FC in the same laboratory at $50 \%$ probability of detection

\begin{tabular}{|c|c|c|c|c|c|c|}
\hline \multirow[b]{2}{*}{ Test method applied } & \multicolumn{2}{|l|}{ Boot swabs } & \multicolumn{2}{|c|}{ Liquid manure sample } & \multicolumn{2}{|c|}{$\begin{array}{l}\text { Combination of boot swab } \\
\text { and liquid manure samples }\end{array}$} \\
\hline & WHP $_{\text {app }} \pm$ S.E. & $95 \% \mathrm{CI}_{\mathrm{app}}$ & $\mathrm{WHP}_{\text {app }} \pm$ S.E. & $95 \% \mathrm{CI}_{\mathrm{app}}$ & $\mathrm{WHP}_{\mathrm{app}} \pm$ S.E. & $95 \% \mathrm{CI}_{\mathrm{apr}}$ \\
\hline FC A & $3 \cdot 31 \pm 0.69$ & $1.94-4.69$ & $2 \cdot 95 \pm 0.60$ & $1 \cdot 74-4 \cdot 15$ & $2 \cdot 51 \pm 0.54$ & $1 \cdot 44-3 \cdot 58$ \\
\hline $\mathrm{FC} \mathrm{B}$ & $4 \cdot 41 \pm 0 \cdot 83$ & $2 \cdot 75-6.08$ & $3.27 \pm 0.67$ & $1.92-4.61$ & $2 \cdot 66 \pm 0.54$ & $1.58-3.74$ \\
\hline FC C & $2 \cdot 54 \pm 0 \cdot 49$ & $1 \cdot 55-3 \cdot 53$ & $9 \cdot 68 \pm 1 \cdot 56$ & $6 \cdot 56-12 \cdot 79$ & $2 \cdot 66 \pm 0 \cdot 54$ & $1 \cdot 58-3 \cdot 74$ \\
\hline PCR A & $5 \cdot 67 \pm 1 \cdot 17$ & $3 \cdot 33-8 \cdot 01$ & $6 \cdot 50 \pm 1 \cdot 21$ & $4 \cdot 08-8 \cdot 92$ & $3.93 \pm 0 \cdot 80$ & $2 \cdot 33-5 \cdot 53$ \\
\hline PCR B & $4 \cdot 53 \pm 0 \cdot 79$ & $2 \cdot 95-6 \cdot 11$ & $3 \cdot 72 \pm 0 \cdot 73$ & $2 \cdot 26-5 \cdot 18$ & $4 \cdot 43 \pm 0.79$ & $2 \cdot 95-6 \cdot 11$ \\
\hline PCR C & $4 \cdot 09 \pm 0 \cdot 94$ & $2 \cdot 21-5 \cdot 97$ & $3 \cdot 12 \pm 0 \cdot 72$ & $1 \cdot 68-4 \cdot 56$ & $1 \cdot 96 \pm 0 \cdot 56$ & $0 \cdot 84-3 \cdot 08$ \\
\hline PCR A + FC A & $2 \cdot 64 \pm 0 \cdot 60$ & $1.44-3 \cdot 83$ & $2 \cdot 84 \pm 0.62$ & $1 \cdot 59-4.08$ & $2 \cdot 40 \pm 0 \cdot 55$ & $1 \cdot 30-3 \cdot 51$ \\
\hline PCR B + FC B & $3 \cdot 55 \pm 0 \cdot 71$ & $2 \cdot 12-4 \cdot 98$ & $2 \cdot 57 \pm 0.56$ & $1 \cdot 44-3 \cdot 70$ & $2 \cdot 36 \pm 0 \cdot 53$ & $1 \cdot 30-3 \cdot 42$ \\
\hline PCR C + FC C & $2 \cdot 39 \pm 0.54$ & $1 \cdot 30-3 \cdot 47$ & $2 \cdot 90 \pm 0.65$ & $1 \cdot 60-4 \cdot 20$ & $1 \cdot 49 \pm 0.39$ & $0 \cdot 70-2 \cdot 28$ \\
\hline
\end{tabular}

$\mathrm{WHP}_{\text {app}}$, Apparent within-herd prevalence; s.E., standard error; $\mathrm{CI}_{\text {app, }}$ approximate confidence interval; MAP, Mycobacterium avium ssp. paratuberculosis; FC, faecal culture; PCR, polymerase chain reaction.

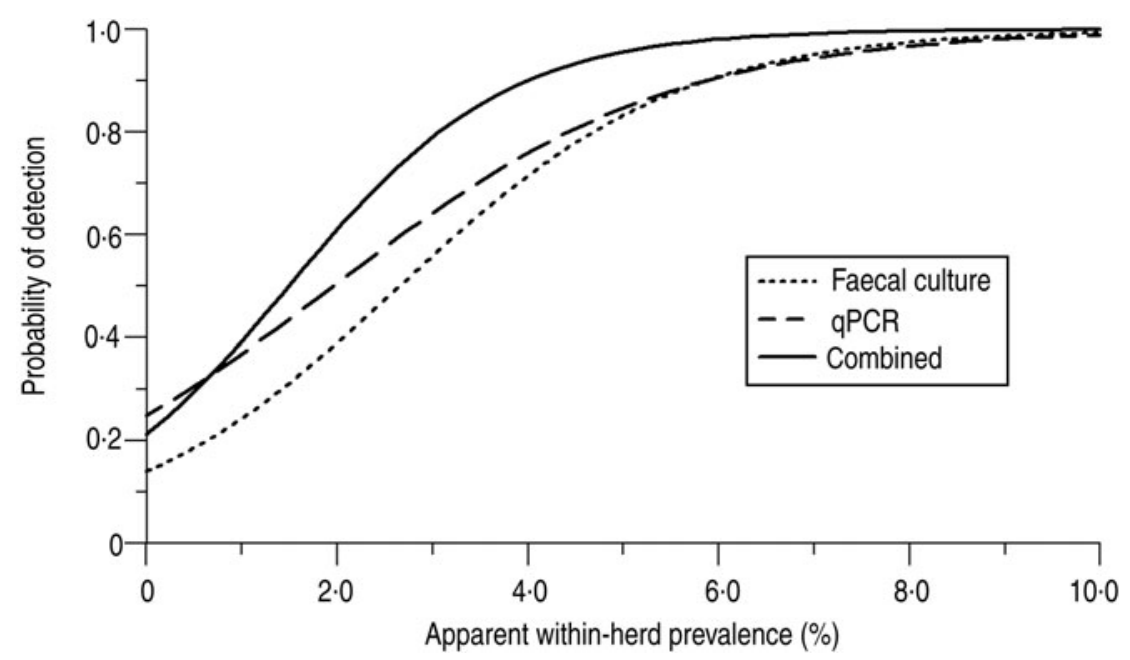

Fig. 1. Logistic functions of the probability of detection using boot swabs and liquid manure samples combined (results from laboratory C).

is not only an alternative for herd diagnosis in lowprevalence herds, but actually shows test characteristics [22, 25] better than those demonstrated for milk ELISA testing at the herd level [15].

Our study aimed to demonstrate that even two samples - one boot swab and one liquid manure sampleare sufficient to identify MAP-positive herds. This study was performed in dairy herds well characterized with regard to their disease status according to the control programme regulations, with either herds not suspected of having paratuberculosis or MAP-positive herds with $\mathrm{WHP}_{\mathrm{app}}$ known from individual faecal culture testing in previous years. This enabled us to calculate thresholds for identifying a herd as MAP-positive from a representative number of 77 study herds with a median $\mathrm{WHP}_{\mathrm{app}}$ of $2 \cdot 4 \%$. The number of herds involved is one strength of our study compared to previous faecal culture-based studies, which applied environmental sampling of seven [19] and 46 herds [20], respectively.

Compared to previous studies [16-18, 24], another strength of our study design is that we used the most sensitive method currently available for the diagnosis of Johne's disease in living animals for the estimation of $\mathrm{WHP}_{\mathrm{app}}$, i.e. individual faecal culture. Due to the 
Table 6. Estimates of $W H P_{\text {app }}$ threshold value \pm asymptotic S.E. and $95 \% C I_{\text {app }}$ for the detection of a MAP-positive herd using a boot swab or a liquid manure sample or the combination of both applying $F C$ (three different laboratories $A, B, C$ ), PCR (three different methods $A, B, C$ ) or the combination of each PCR with FC in the same laboratory at $90 \%$ probability of detection

\begin{tabular}{|c|c|c|c|c|c|c|}
\hline \multirow[b]{2}{*}{ Test method applied } & \multicolumn{2}{|l|}{ Boot swabs } & \multicolumn{2}{|c|}{ Liquid manure sample } & \multicolumn{2}{|c|}{$\begin{array}{l}\text { Combination of boot swab } \\
\text { and liquid manure samples }\end{array}$} \\
\hline & $\mathrm{WHP}_{\mathrm{app}} \pm$ s.E. & $95 \% \mathrm{CI}_{\mathrm{app}}$ & $\mathrm{WHP}_{\mathrm{app}} \pm$ S.E. & $95 \% \mathrm{CI}_{\mathrm{app}}$ & $\mathrm{WHP}_{\mathrm{app}} \pm$ s.E. & $95 \% \mathrm{CI}_{\mathrm{app}}$ \\
\hline $\mathrm{FC} \mathrm{A}$ & $7 \cdot 69 \pm 1 \cdot 53$ & $4 \cdot 63-10 \cdot 74$ & $6 \cdot 57 \pm 1 \cdot 33$ & $3 \cdot 91-9 \cdot 23$ & $5 \cdot 79 \pm 1 \cdot 19$ & $3 \cdot 41-8 \cdot 17$ \\
\hline $\mathrm{FC} \mathrm{B}$ & $9 \cdot 63 \pm 1 \cdot 81$ & $6 \cdot 02-13 \cdot 25$ & $7 \cdot 41 \pm 1 \cdot 50$ & $4 \cdot 40-10 \cdot 41$ & $5 \cdot 87 \pm 1 \cdot 18$ & $3 \cdot 52-8 \cdot 22$ \\
\hline $\mathrm{FC} \mathrm{C}$ & $5 \cdot 29 \pm 1 \cdot 05$ & $3 \cdot 19-7 \cdot 39$ & $17 \cdot 26 \pm 3 \cdot 10$ & $11 \cdot 05-23 \cdot 46$ & $5 \cdot 86 \pm 1 \cdot 17$ & $3 \cdot 52-8 \cdot 21$ \\
\hline PCR A & $13 \cdot 70 \pm 2 \cdot 82$ & $8 \cdot 06-19 \cdot 34$ & $13 \cdot 71 \pm 2 \cdot 70$ & $8 \cdot 31-19 \cdot 11$ & $9 \cdot 10 \pm 1 \cdot 78$ & $5 \cdot 54-12 \cdot 66$ \\
\hline PCR B & $9 \cdot 01 \pm 1 \cdot 60$ & $5 \cdot 81-12 \cdot 21$ & $7 \cdot 55 \pm 1 \cdot 52$ & $4 \cdot 51-10 \cdot 59$ & $9 \cdot 01 \pm 1 \cdot 60$ & $5 \cdot 81-12 \cdot 21$ \\
\hline PCR C & $10 \cdot 73 \pm 2 \cdot 26$ & $6 \cdot 21-15 \cdot 25$ & $7 \cdot 73 \pm 1 \cdot 66$ & $4 \cdot 41-11 \cdot 05$ & $5 \cdot 86 \pm 1 \cdot 35$ & $3 \cdot 16-8 \cdot 56$ \\
\hline PCR A + FC A & $6 \cdot 49 \pm 1 \cdot 36$ & $3 \cdot 77-9 \cdot 22$ & $6 \cdot 77 \pm 1 \cdot 42$ & $3 \cdot 93-9 \cdot 62$ & $5 \cdot 96 \pm 1 \cdot 27$ & $3 \cdot 43-8 \cdot 50$ \\
\hline $\mathrm{PCR} B+\mathrm{FC} \mathrm{B}$ & $8 \cdot 05 \pm 1 \cdot 57$ & $4 \cdot 90-11 \cdot 19$ & $6 \cdot 08 \pm 1 \cdot 28$ & $3 \cdot 52-8 \cdot 65$ & $5 \cdot 70 \pm 1 \cdot 20$ & $3 \cdot 30-8 \cdot 11$ \\
\hline $\mathrm{PCR} C+\mathrm{FC} \mathrm{C}$ & $5 \cdot 85 \pm 1 \cdot 24$ & $3 \cdot 37-8 \cdot 33$ & $7 \cdot 10 \pm 1 \cdot 51$ & $4 \cdot 08-10 \cdot 11$ & $3.99 \pm 0.90$ & $2 \cdot 19-5 \cdot 79$ \\
\hline
\end{tabular}

$\mathrm{WHP}_{\text {app }}$, Apparent within-herd prevalence; s.E., standard error; $\mathrm{CI}_{\mathrm{app}}$, approximate confidence interval; MAP, Mycobacterium avium ssp. paratuberculosis; FC, faecal culture; PCR, polymerase chain reaction.

higher sensitivity and specificity of faecal culture, studies that estimated $\mathrm{WHP}_{\text {app }}$ by direct detection of the organism in individual samples from each animal [19-21] are less susceptible to misclassification bias than those using identification based on the detection of antibodies against MAP or pooled samples. Therefore, our $\mathrm{WHP}_{\text {app }}$ estimation was not influenced by any bias as can be anticipated after pooling, resulting in more precise data. This is particularly important in herds with low prevalence. Nonetheless, some uncertainty remains as a result of the suboptimal sensitivity of faecal culture, which is estimated to be approximately $60 \%$ relative to tissue culture [22]. We decided to refer to the faecal culture-based $\mathrm{WHP}_{\text {app }}$ because necropsy followed by tissue culture is not a realistic option for diagnosis in the framework of control programmes or field studies. Furthermore, the estimation of $\mathrm{WHP}_{\text {app }}$ was animal-based, and it cannot be ruled out that intermittent shedding by low shedders may cause some variability in the faecal culture outcome. In addition, at least in Thuringia, not all cows present in the herd on the day of environmental sampling had been tested; only those that had been sampled previously had, resulting in an average proportion of tested cows of $86.8 \%$ (Table 1). This may have led to an underestimation of WHP $_{\text {app }}$ in herds with more shedders among the non-tested cows compared to the tested ones, or vice versa. We accepted this potential misclassification bias, as the percentage of non-tested cows was far smaller than the percentage of those tested. As such, this uncertainty cannot be excluded from the WHP $_{\text {app }}$ estimation.

As the measured values of both MAP detection tests $\left(\mathrm{C}_{\mathrm{t}}\right.$ values for PCR, colony growth score for faecal culture) showed a highly significant association with $\mathrm{WHP}_{\text {app }}$ (Table 3), we calculated a logistic regression for both methods separately and for the combination of the faecal culture with PCR applied on boot swab or liquid manure samples for each laboratory (Table 4). As expected, the use of two test methods simultaneously increased the OR resulting from the logistic regression model, demonstrating a higher chance of identifying a herd as MAP positive when $\mathrm{WHP}_{\text {app }}$ increases. Consequently, the outcome of the $\mathrm{WHP}_{\mathrm{app}}$ threshold estimation by the logistic model showed the same effect. Applying two tests resulted in lower $\mathrm{WHP}_{\text {app }}$ estimates in boot swabs, liquid manure samples and the combination of both matrices, respectively. Applying faecal culture (all laboratories) or PCR $\mathrm{C}$ to a combined boot swab and liquid manure sample, the estimate was lower compared to the use of only one matrix, apart from boot swabs tested by faecal culture in laboratory $\mathrm{C}$ (Tables 5 and 6). These markedly good results may be explained by the laboratory's many years of experience with faecal culture as Germany's national reference laboratory for paratuberculosis. This result may encourage the application of faecal culture on boot swabs alone, if the laboratory ensures a high standard for this test method. 
The lowest estimates were calculated for the combination of faecal culture and PCR in laboratory C for a combined boot swab and a liquid manure sample with $1.5 \%$ at $50 \% \mathrm{P}_{\mathrm{d}}$ and $4.0 \%$ at the $90 \% \mathrm{P}_{\mathrm{d}}$ level. These values clearly demonstrate that using a combination of one boot swab and one liquid manure sample is sufficiently sensitive to identify dairy herds with a low prevalence of MAP shedders at an acceptable probability level. Even boot swabs alone performed rather satisfactorily, with estimated thresholds of about $2 \cdot 4 \%$ at $50 \% P_{\mathrm{d}}$ and $5.8 \%$ at $90 \% P_{\mathrm{d}}$. This is of considerable practical value as boot swabs are very easy to sample, pack and ship. Nonetheless, our results show that the combination of both matrices, one sample collected in cow concentration areas and the other one representing manure storage areas, leads to the most reliable outcome. Although the application of two methods on one sample appears to be elaborative and expensive, it is worthwhile as part of control programmes because it enhances the application options of environmental sampling. The detection limit of about $4 \%$ at $90 \% \quad P_{\mathrm{d}}$ enables the use of environmental sampling as a reliable screening tool. The $90 \% P_{\mathrm{d}} \mathrm{WHP}_{\text {app }}$ threshold gives an indication of what can be expected from the use of single sampling in voluntary control programmes or prevalence studies. It is important to identify herds with a high $\mathrm{WHP}_{\text {app }}$ because these herds represent the highest risk of MAP shedding into the food chain and the environment. In voluntary control programmes, these farms should be identified and given priority by consultants in order to enable the immediate introduction of control measures.

The reduction to $1 \cdot 5 \%$ at $50 \% P_{\mathrm{d}}$ may allow herds not suspected of having paratuberculosis to be monitored in certification programmes, at least for herds with fewer than 50 cows, taking into account the following: In those herds, one shedder will cause a $\mathrm{WHP}_{\mathrm{app}}$ of $\geqslant 2 \%$, which means that, theoretically, environmental sampling has the potential to detect all herds of this size in which there is one MAP shedder. Repeated sampling will not further reduce the WHP $_{\text {app }}$ threshold, but it enhances the $P_{\mathrm{d}}$ at a certain $\mathrm{WHP}_{\text {app }}$ level. Assuming, for example, five statistically independent observations of boot swab and liquid manure samplings with the calculated $\mathrm{WHP}_{\text {app }}$ threshold of $1.5 \%$ at $P_{\mathrm{d}}$ of $50 \%$, the resulting $P_{\mathrm{d}}$ would be $96.9 \%$ and, therefore, acceptable. Despite concerns with respect to the misclassification of low-prevalence MAP-positive herds as 'false MAP-negative' by using solely environmental samples [19-21], our results encourage the application of environmental sampling to monitor herds certified as not suspected of having paratuberculosis under certain conditions. Serious limitations remain for the use of environmental sampling to monitor large herds, especially in multi-site housing systems.

Taken together, these results confirm the hypothesis that boot swabs and liquid manure samples are an efficient means of identifying MAP-positive dairy herds. We favour a combination of one boot swab and one liquid manure sample tested simultaneously by faecal culture and PCR. This approach is suitable for identifying MAP-positive dairy herds at an acceptable probability level even if the $\mathrm{WHP}_{\text {app }}$ is low.

The use of one boot swab sample alone impairs the detectable $\mathrm{WHP}_{\text {app }}$ threshold to a certain degree, but is still a useful approach. Further research is required in a longitudinal study to evaluate the repeated use of boot swabs and liquid manure samples in herds previously certified as not suspected of having paratuberculosis, particularly in order to detect a reintroduction of the infectious agent.

\section{ACKNOWLEDGEMENTS}

This joint research project was undertaken and financed by the animal health services of three German federal states (organizing institutions: Hessian State Laboratory, Hesse State Council, Saxon Animal Disease Fund, Thuringian Animal Disease Fund). The authors thank all institutions for their support. Furthermore, the authors gratefully acknowledge the financial support by the Thuringian Dairy Industry Association (Landesvereinigung Thüringer Milch e.V.) and the Hessian Animal Disease Fund. Above all, the authors would like to thank the dairy farmers who participated, the laboratory staff, all veterinarians who collected samples, and Matthew Rockey for improving the English.

\section{DECLARATION OF INTEREST}

None.

\section{REFERENCES}

1. Tiwari A, et al. Johne's disease in Canada Part I: clinical symptoms, pathophysiology, diagnosis, and prevalence in dairy herds. Canadian Veterinary Journal 2006; 47: 874-882.

2. Whitlock RH, et al. Prevalence and economic consideration of Johne's disease in the north-eastern U.S. 
Proceedings of the United States Animal Health Association 1985; 89: 484-490.

3. Raizman EA, et al. The association between culling due to clinical Johne's disease or the detection of Mycobacterium avium subsp. paratuberculosis faecal shedding and the diagnosis of clinical or subclinical diseases in two dairy herds in Minnesota, USA. Preventive Veterinary Medicine 2007; 80: 166-178.

4. Smith RL, et al. Effect of Johne's disease status on reproduction and culling in dairy cattle. Journal of Dairy Science 2010; 93: 3513-3524.

5. Gonda MG, et al. Identification of a QTL on BTA20 affecting susceptibility to Mycobacterium avium ssp. paratuberculosis infection in US Holsteins. Animal Genetics 2007; 38: 389-396.

6. Beaudeau $\mathbf{F}$, et al. Reduction in milk yield associated with Mycobacterium avium subspecies paratuberculosis (Map) infection in dairy cows. Veterinary Research 2008; 38: 625-634.

7. Raizman EA, et al. Loss of income from cows shedding Mycobacterium avium subspecies paratuberculosis prior to calving compared with cows not shedding the organism on two Minnesota dairy farms. Journal of Dairy Science 2009; 92: 4929-4936.

8. Smith RL, et al. A longitudinal study on the impact of Johne's disease status on milk production in individual cows. Journal of Dairy Science 2009; 92: 2653-2661.

9. Feller M, et al. Mycobacterium avium subspecies paratuberculosis and Crohn's disease: a systematic review and meta-analysis. Lancet Infectious Diseases 2007; 9: 607-613.

10. Uzoigwe JC, et al. Epidemiological evidence for Mycobacterium avium subspecies paratuberculosis as a cause of Crohn's disease. Epidemiology and Infection 2007, 135: 1057-1068.

11. Collins MT. Diagnosis of paratuberculosis. Veterinary Clinics of North America: Food Animal Practice 2011; 27: 581-591.

12. Sweeney RW. Pathogenesis of paratuberculosis. Veterinary Clinics of North America: Food Animal Practice 2011, 27: 537-546.

13. Pozzato N, et al. Evaluation of a rapid and inexpensive liquid culture system for the detection of Mycobacterium avium subsp. paratuberculosis in bovine faeces. Journal of Microbiological Methods 2011; 84: 413-417.

14. Donat K, et al. Herd prevalence studies of Mycobacterium avium ssp. paratuberculosis (MAP) in cattle using serological tests: Opportunities, limitations and costs. Berliner und Münchner Tierärztliche Wochenschrift 2012; 125: 361-370.

15. Lavers CJ, et al. Evaluation of milk ELISA for detection of Mycobacterium avium subspecies paratuberculosis in dairy herds and association with within-herd prevalence. Journal of Dairy Science 2014; 97: 299-309.

16. Raizman EA, et al. The distribution of Mycobacterium avium ssp. paratuberculosis in the environment surrounding Minnesota dairy farms. Journal of Dairy Science 2004; 87: 2959-2966.

17. Berghaus RD, et al. Use of age and milk production data to improve the ability of enzyme-linked immunosorbent assay test results to predict $\mathrm{Myco}$ bacterium avium ssp. paratuberculosis faecal culture status. Journal of Dairy Science 2006; 89: 963-970.

18. Lombard JE, et al. Evaluation of environmental sampling and culture to determine Mycobacterium avium subspecies paratuberculosis distribution and herd infection status on US dairy operations. Journal of Dairy Science 2006; 89: 4163-4171.

19. Pillars RB, et al. Prevalence of Michigan dairy herds infected with Mycobacterium avium subspecies paratuberculosis as determined by environmental sampling. Canadian Veterinary Journal 2009; 50: 1039-1046.

20. Donat K, et al. Identification of Mycobacterium avium ssp. paratuberculosis infected dairy herds by environmental sampling. Berliner und Münchner Tierärztliche Wochenschrift 2011; 124: 10-17.

21. Smith RL, et al. Environmental contamination with Mycobacterium avium subsp. paratuberculosis in endemically infected dairy herds. Preventive Veterinary Medicine 2011; 102: 1-9.

22. Sweeney RW, et al. Paratuberculosis (Johne's disease) in cattle and other susceptible species. Journal of Veterinary Internal Medicine 2012; 26: 1239-1250.

23. Lombard JE, et al. Herd-level prevalence of Mycobacterium avium subsp. paratuberculosis infection in United States dairy herds in 2007. Preventive Veterinary Medicine 2013; 108: 234-238.

24. Lavers CJ, et al. Evaluation of environmental faecal culture for Mycobacterium avium subspecies paratuberculosis detection in dairy herds and association with apparent within-herd prevalence. Canadian Veterinary Journal 2013; 54: 1053-1060.

25. Donat K, et al. Detection of Mycobacterium avium subspecies paratuberculosis in environmental samples by faecal culture and real-time PCR in relation to apparent within-herd prevalence as determined by individual faecal culture. Epidemiology and Infection 2015; 143: 975-985.

26. Eisenberg T, et al. Boot swabs to collect environmental samples from common locations in dairy herds for Mycobacterium avium ssp. paratuberculosis (MAP) detection. Journal Dairy Research 2013; 80: 485-489.

27. Wolf R, et al. Evaluation of an alternative environmental sampling method for the detection of MAP. In: Proceedings of the 12th International Colloquium on Paratuberculosis. Providence: International Association for Paratuberculosis, 2014, p. 219.

28. Lovel R, et al. Studies on the survival of Johne's bacilli. Journal of Comparative Pathology 1944; 54: 120-129.

29. Jørgensen JB. Survival of Mycobacterium paratuberculosis in slurry. Nordisk veterinaermedicin 1977; 29: 267-270.

30. Logar K, et al. Evaluation of combined high-efficiency DNA extraction and real-time PCR for detection of Mycobacterium avium subsp. paratuberculosis in subclinically infected dairy cattle: comparison with faecal culture, milk real-time PCR and milk ELISA. BMC Veterinary Research 2012; 8: 49.

31. Dressel J. Comparative study concerning the direct detection of Mycobacterium avium ssp. paratuberculosis in bovine faeces (diploma thesis) [in German]. 
32. Thüringer Ministerium für Soziales, Familie und Gesundheit. Johne's disease control programme in cattle herds in Thuringia [in German]. Thüringer Staatsanzeiger 2008; 18: 556-558.

33. Saxon Animal Diseases Fund (http://www.tsk-sachsen. de/index.php/rindergesundheit/leistungen-a-programme/96paratuberkulose-programm). Accessed 12 February 2015.

34. United States Department of Agriculture (USDA). Animal and Plant Health Inspection Service. Uniform program standards for the voluntary bovine Johne's Disease Control Program, effective 1 September 2010 (http://www.aphis.usda.gov/animal_health/animal_diseases/ johnes/downloads/johnes-ups.pdf). Accessed 27 February 2014.

35. Anon. Official Manual of Diagnostic Procedures, release April 2012 [in German]. (http://www.fli.bund.de/ fileadmin/dam_uploads/Publikationen/Amtliche_Method ensammlung/Methodensammlung_201204.pdf). Accessed 15 August 2013.

36. Englund S, et al. Single PCR and nested PCR with a mimic molecule for detection of Mycobacterium avium subsp. paratuberculosis. Diagnostic Microbiology and Infectious Disease 1999; 33: 163-171.

37. Schönenbrücher $\mathbf{H}$, et al. New triplex real time PCR assay for detection of Mycobacterium avium subsp. paratuberculosis in bovine feces. Applied and Environmental Microbiology 2008; 74: 2751-2758.

38. Fawzy A, et al. Improvement of sensitivity for Mycobacterium avium subsp. paratuberculosis detection in bovine fecal samples by specific duplex F57/IC realtime and conventional IS900 PCRs after solid culture enrichment. Tropical Animal Health and Production. Published online: 26 February 2015. doi:10.1007/ s11250-015-0784-9.

39. Hoffmann B, et al. A universal heterologous internal control system for duplex real-time RT-PCR assays used in a detection system for pestiviruses. Journal of Virological Methods 2006; 136: 200-209.

40. Dixon WJ (ed.). BMDP Statistical Software Manual, volumes I and II. Berkeley, Los Angeles, London: University of California Press, 1993, pp. 775-794, 1105-1144. 